\title{
Efeito do tratamento com cefalexina sobre a contagem de cúlas somáticas de vacas e quartos infectados com Streptococcus agalactiae
}

Bruno Sivieri de Lima ${ }^{[]^{*}}$, Ronaldo Carvalho Macedo ${ }^{[b]}$, Leandro Carlos Pereira ${ }^{[a]}$, Decuadro-Hansen ${ }^{[c]}$,Eryich Osvaldo Ara Nunes ${ }^{[a]}$, Luc Durel[d]

\author{
[a] Virbac do Brasil, São Paulo, SP, Brasil \\ [b] Cia do Leite Ltda, Lavras, MG, Brasil \\ [c] Virbac Latam, Buenos Aires, Argentina \\ [d] Virbac França, Carros, Alpes-Maritimes, França
}

*Autor correspondente

e-mail: bruno.lima@virbac.com.br

\section{Resumo}

Streptococcus agalactiae é uma bactéria Gram+ que causa infecção intramamária subclínica altamente contagiosa em vacas. Em rebanhos infectados, a prevalência de infecções intramamárias subclínicas por Streptococcus agalactiae pode ser muito elevada e ter impacto negativo na contagem de células somáticas individuais (CCS). 0 objetivo deste estudo foi confirmar a eficácia de um medicamento à base de cefalexina (Rilexine 200 - Virbac Saúde Animal, Brasil), administrado via intramamária para o controle de Streptococcus agalactiae em rebanhos leiteiros, bem como o impacto sobre CCS. Foram utilizados dados de rebanhos leiteiros localizados na região sul do Estado de Minas Gerais, que adotaram um programa de controle de mastite contagiosa com o tratamento de Streptococcus agalactiae como medida complementar do programa. Amostras de leite (pull quatro quartos) foram coletadas de todas as vacas em lactação e enviadas ao laboratório para cultura bacteriana e CCS. Vacas positivas para Streptococcus agalactiae foram tratadas, independentemente do estágio de lactação e idade. Os quatro quartos das vacas positivas foram tratados via intramamária com Cefalexina (100 mg), Neomicina (100 mg) e Prednisolona (10 mg), com intervalos de 12 horas, três administrações consecutivas. Vinte e um dias após o último tratamento, foram coletadas novas amostras de leite dos animais tratados com o objetivo de avaliar a taxa de cura aparente e o impacto na CCS. Entre outubro de 2015 e dezembro de 2016, foram coletadas amostras de 617 animais em 14 fazendas. 176 vacas foram identificadas positivas para Streptococcus agalactiae e 126 vacas foram tratadas. De todas as vacas tratadas, 115 de 126 foram identificadas como bacteriologicamente curadas 
no dia 21 (91,3\%; min. 82.5\% - max. 100.0\%). Ao longo do período de estudo, a média de CCS do leite do tanque das 14 fazendas diminuiu significativamente, em média de 1.176 para $727 \times 10^{3}$ células $/ \mathrm{ml}(\mathrm{P}=0,03$, teste-t, one tail). Em vacas leiteiras, as infecções intramamárias causadas por Streptococcus agalactiae são susceptíveis à terapia antimicrobiana, incluindo a cefalexina. 0 tratamento de animais infectados, associado a estratégias de manejo, deve ser considerado para evitar o descarte prematuro de animais com alto valor genético. Conclui-se que o protocolo com Rilexine 200 deve ser considerado para o tratamento de animais positivos com Streptococcus agalactiae. 